\title{
Impact of Agricultural Electricity for Hubei Province Economy Development of County Territory
}

\author{
An Empirical Study of Hubei County \\ Xiaohong Fang, Chengwei Zhang and Ge Guo* \\ School of Management, Wuhan Donghu University, Wuhan 430200, China; \\ 2497507286@qq.com,84695056@qq.com \\ *The corresponding author
}

Keywords: Internet +; Agricultural electricity; Economic development; The county economy

\begin{abstract}
In recent years, the tide of the Internet is changing people's lives rapidly. So life is more convenient and efficient and rich. China is an agricultural country, the combination of the Internet + agriculture will bring profound changes to agriculture, rural areas and farmers. It is beneficial to the development of industries with regional features, is beneficial to the formation of regional brand. Enhance the core competitiveness and promote the development of local economy.
\end{abstract}

\section{Literature Review}

County economy self-development ability is the result of research on self-development ability of regional economy, foreign earlier research on self-development ability of regional economy, and in the domestic, first of all, who studies self-development ability of regional economy is Lin. Lin, puts forward the concept of viability, he thinks oneself ability is in the competitive market conditions, if the enterprise in the absence of external forces intervention and support can obtain expected profit of the industry, is the industry or enterprise's viability. At the same time, Lin also pointed out in the competitive market structure, its capacity is very important to industry or enterprise, a business or enterprise without their own ability is caused by unreasonable or structure of factor endowments. Li yining think county economy as part of the regional economy, county economy at the same time self development as regional self-development ability is an important content of China's regional economic fundamentals and an important link of the coordination of urban and rural relationship, made an important contribution to the development of China's regional economy. As a new kind of different from traditional trade mode, e-commerce will production enterprises, circulation enterprises and consumers and the government introduced a digital virtual space, make people no longer subject to geographical and time constraints, in a very simple and quick way to complete the more complicated business activities, the manual and electronic information processing integration as an integral whole, optimize the resource configuration, improve the rigor and efficiency of system operation. Therefore, the development of agricultural e-commerce impact on the county economy and the life is various.

\section{Problem Description}

The central file no. 1 in 2016 specifically to support agricultural e-commerce platform construction, the rural electricity get a better development opportunities. Internet+ agriculture is to realize the modernization of agriculture by the Internet+, its fundamental is to improve the competitiveness of the agricultural industry, to increase farmers' income, realize the sustainable development of agriculture. Internet+ speed up the development of agricultural modernization, has brought historic opportunity. Reduce production cost, improve agricultural economic benefit, shorten the distance of products to the table, also can help agricultural solve the problem of information asymmetry of unsalable, reduce agricultural products market risk and economic loss, this is what the Internet gives the new opportunity of agriculture. Is it benifinal for developing the 
local economy? Agricultural electricity development of hubei province influence county territory economy development? Whether very significant role in promoting, the local government in promoting agricultural electricity and can do what work?

\section{Research Design}

In this paper, using factor analysis method to construct the index system of the county economy of Hubei province self-development capacity. These are selected a handful of comprehensive index to reflect the most and the main information of the original data and structure. Described in the study of regional economy, a lot of statistical indicators comprehensive features in a region, can be extracted from the comprehensive index of several major factors, not only can analyze the main influencing factors of an observation, also reduced the information content of less data, eliminating the irrelevant information, simplify the data structure. Agricultural electricity, respectively, the influence degree of the development of county economy of hubei province before and after.

This article selects the 56 in different county of hubei agricultural enterprises as the research object, the sample data from a questionnaire survey of raw data, enterprise distribution covers agricultural services, agricultural cultivation, deep processing of agricultural products of different types.

Table 1 Sample distribution

\begin{tabular}{|c|c|c|c|c|c|c|c|c|c|}
\hline \multicolumn{10}{|c|}{56 enterprises distribution } \\
\hline Item & \multicolumn{3}{|c|}{ agricultural services } & \multicolumn{3}{|c|}{ agricultural cultivation } & \multicolumn{3}{|c|}{ deep processing } \\
\hline Category & LuoTian & YingShan & Jia Yu & LuoTian & YingShan & JiaYu & Luotian & YingShan & JiaYu \\
\hline $\begin{array}{l}\text { Sample } \\
\text { size }\end{array}$ & 5 & 3 & 4 & 6 & 4 & 8 & 10 & 6 & 10 \\
\hline Total & \multicolumn{3}{|c|}{12} & \multicolumn{3}{|c|}{18} & \multicolumn{3}{|c|}{26} \\
\hline Percentage & \multicolumn{3}{|c|}{$21 \%$} & \multicolumn{3}{|c|}{$32 \%$} & \multicolumn{3}{|c|}{$47 \%$} \\
\hline
\end{tabular}

56 enterprises were extracted respectively before and after the introduction of electrical business model, enterprise in operating income, operating cost, operating profit, cost of sales, sales mode (online sales ratio), the growth of foreign trade, income growth, return on investment, enterprise income tax, net profit, the profit of the total amount of data. Using the factor analysis method to construct comprehensive evaluation index system of the county economy of hubei province self-development ability need to examine the correlation between indicators before. This article USES the bartlett sphericity test method and the KMO test methods for three county, hubei province agricultural enterprise evaluation index variable correlation between 11 inspection, inspection results showed that bartlett sphericity test statistics the observed value of the corresponding probability $\mathrm{p}$ values are less than 0.01 , which refused to correlation coefficient matrix is a unit matrix of the original assumption, that the correlation coefficient matrix with the unit matrix have significant differences, the original variable for factor analysis, and at the same time, KMO test results mean value is 0.812 , shows that the original variable correlation is stronger, is suitable for factor analysis.

Extract the common factor, set to extract common factor for 4, use SPSS for analysis. Find eigenvalues greater than 1 , the common factor of the cumulative contribution rate reached more than $80 \%$, after rotating the factor loading matrix, and the four common factor can be found separately reflects on economic growth, economic structure, economic relations, the influence of tax contribution. 
Table 2 Rotated component matrix

\begin{tabular}{|c|c|c|c|c|}
\hline & & & onent & \\
\hline & 1 & 2 & 3 & 4 \\
\hline $\mathrm{X} 1$ & .832 & .078 & .158 & .008 \\
\hline$X 2$ & .945 & .065 & .085 & .306 \\
\hline$x 3$ & .876 & .035 & .098 & .108 \\
\hline$X 4$ & .408 & -.450 & .078 & .674 \\
\hline$\times 5$ & .102 & .008 & .140 & .794 \\
\hline$x 6$ & .153 & .024 & .356 & .907 \\
\hline $\mathrm{X7}$ & -.006 & .968 & .045 & .032 \\
\hline$x 8$ & .027 & .942 & .008 & .285 \\
\hline$\times 9$ & -.025 & .875 & .178 & .095 \\
\hline $\mathrm{X} 10$ & .298 & .009 & .954 & .029 \\
\hline $\mathrm{X} 11$ & .046 & .056 & .893 & .319 \\
\hline
\end{tabular}

From economic growth, economic structure, economic relations, tax contribution index system is constructed to four dimensions to measure the impact on the local economic development. According to the result of principal component load further corresponding principal component scores of each county, Hubei province, at the same time, in order to better reflect the ability of the county economy in Hubei province to self-development has carried on the weighted sum of each factor, so we can get the county economy of Hubei province self-development ability score.

Table 3 The contribution rate factors

\begin{tabular}{|c|c|c|c|c|c|}
\hline & 1 & 2 & 3 & 4 & Total \\
\hline \% of Variance & 25.245 & 24.852 & 17.756 & 12.652 & 80.118 \\
\hline Weight & 0.32 & 0.31 & 0.22 & 0.15 & 1 \\
\hline
\end{tabular}

\section{$\mathrm{F}=0.32 \mathrm{~F}_{1}+0.31 \mathrm{~F}_{2}+0.22 \mathrm{~F}_{3}+0.15 \mathrm{~F}_{4}$}

According to the common factor to the interpretation of the original variable capacity, to get the weight of common factor impact on economic growth, so as to set up the implementation of the electricity impact before and after, on the economic development of the comprehensive evaluation model. According to the score model function, score can be calculated without electricity business operating model and implementing the comprehensive after electric business operation model.

\section{The Empirical Results}

E-commerce are profoundly changing the economy, market and industrial structure; Changing the product, service, and its flow; Changing consumer values and behavior; And changing employment and labor market, e-commerce as an important motivation of economic development factors, the positive influence to some extent the comprehensiveness and the overall economy. Can from the perspective of consumers, producers and sellers change the way of economic exchanges, guaranteeing the rapid feedback of information and economy to communicate. Has a small enterprise inventory pressure, speed, and the advantages of the link less, can promote the development of the high-tech companies, realize the optimization and upgrading of traditional industrial structure, economic development and the development of modern logistics industry growth point. E-commerce subverts the traditional circulation pattern, reduce the intermediate links, make producers and consumers can direct trading, fundamentally change the way the whole social economic operation. 
The application of electronic commerce in the region of the total supply and total demand will produce very big effect, one is the electronic commerce will encourage enterprises expanding, increased efficiency and comprehensive cost is reduced; The second is due to cutting costs, companies with large-scale procurement, the premise of expanding production conditions; Last when e-commerce is widely used in the territory, will make the mass market sales and consumption increased rapidly. The development of electronic commerce can meet the needs of consumers and businesses to promote regional enterprise fast development, the electronic commerce will promote regional economic growth

It is greatly different, on the Internet shopping websites a dime a dozen, website commodity is also drench ranging, customers can be in any a shopping site, click, browse, comparison and selection of space increases, shopping no pressure, don't have to consider the sales staff, no longer subject to the interference of man-made factors, to better choose their own like commodities. At present a lot of small and medium-sized agricultural enterprises in Hubei by e-commerce realize the successful transformation, enterprises have a good development. Electronic business service industry also shows a tendency of diversification and rapid development, produce a large number of new types of small and medium-sized enterprises and new jobs, small and medium-sized enterprise electronic commerce application scale expands rapidly, has become a national economy sustained growth momentum. Rural urbanization will become a reality, massive amounts of personal consumption as the popularity of the Internet more and more high, especially the support of information industry, the rapid development of the regional market e-commerce, the wide application of e-commerce will promote the rapid benign growth of regional economy.

\section{Research Conclusions and Recommendations}

First for agricultural electricity, the government should increase the intensity of investment promotion and capital introduction, guide the urban capital, technology, talents and other factors of production flow to the rural, focus on encouraging rural city industrial and commercial enterprises to build high-quality agricultural products, production and processing base, support agricultural products deep processing, key technology research and development, To develop the deep processing of agricultural products, at the same time, the agricultural products from the packaging design meticulously, storage, transportation, order processing, wholesale business to the terminal retail industry chain each link. Efforts to build a complete industrial chain, so as to improve agricultural productivity and labor productivity, allow farmers to share more value-added benefits of agricultural products. Today when the development of the Internet, the development of large data for building data platform of the direct dialogue, I believe that establishes the technical feasibility of today, we will see more business model, want to do now is some real innovation once or partial to innovation in the production of terminal, management subject to financial institutions and leading enterprises to establish a closer new operating model based on the Internet.

The second is the improvement of the infrastructure. Network infrastructure. "Coverage Internet" engineering construction vigorously, telecom, mobile, unicom, radio and television to accelerate realizing a complete coverage of broadband in rural areas, to ensure that rural masses can timely, convenient to carry out the electronic commerce information query, distribution, trade, etc., For rural electronic commerce development to provide the most basic network security, to continuously improve to promote broadband network speed, implement preferential access rate and higher rate of access. In addition, to improve the online payment and the financial system, build credit and certification system, and promote technological innovation, set up perfect electronic commerce the public service system. Integration of express logistics resources. Vigorously develop the third party logistics, improve the level of socialization of logistics distribution, organization and information, provide fast and efficient logistics support for online transactions. Supporting the construction of key e-commerce enterprise logistics center. The future of our country should speed up the building to the public welfare services, business services and self-services, special services and the combination of comprehensive coordinated service of new agricultural socialized service system. 
Finally is suitable for factory production of planting scale. Factory farming also calls the facility agriculture, under the condition of the controlled environment, the industrialization mode of production, Can effectively use of modern industrial technology and facilities and equipment agriculture, to get rid of the bondage of the natural environment and conditions for agricultural production, using modern management and production means of industrialization is engaged in agricultural production, improve labor productivity and land productivity, make more reasonable and efficient use of resources, make the agricultural products market share is greatly increased, it is helpful for the development of the county economy.

\section{Acknowledgement}

This work was supported by the grants from Hubei Provincial Collaborative Innovation Centre of Agricultural E-Commerce( under Construction)(Wuhan Donghu university research [2015] No. 11 Document).

\section{References}

[1] Jonson,S.La,Porta,R.Lopez-de-Silanes,F,Shleifer,A.(2012),Tunnelin,[J].American Economic Review(2): 95-99.

[2] Mc Connell John J.and henri servae.(1990),Additional Evidence on Ownership

[3] and Corporates Value [J]. Journal of financial economics, 595-612.

[4] Berle A, Means G.The modern corporation and private property [M]. Newyork: Commerce clearing house,:200-205.

[5] G Li, teach rural e-commerce development [D] 2014 agricultural management cadre institute, (4) $17-18$.

[6] W.G Ma, new rural construction problems existing in information service.

[7] [J] agricultural network information 2015, (9) 24-26.

[8] Y Lin, the reflection of the economic transformation and new classical.

[9] economics [J]. Journal of economic research, 2002 (12) : 15 to 24.

[10] Y.N , who thinks of the regional development new ideas [M]. Beijing.

[11] economic daily press, 2000.

[12]R Guo, Regional economics definition and self-development ability experience meaning [J]. Journal of economic issues, 2013 (7) : 14 to 18 .New.

[13] Y Li, contend in beauty. The western national regions self-development ability evaluation and influence factors analysis [J]. Guangxi minorities research, 2013 (3) : 161-169.

[14] Information on www. Englishexpress.com. 